\title{
Surgical removal of a hepaticogastrostomy stent because of its recurrent dislocation into the esophagus
}

For endoscopic ultrasound-guided hepaticogastrostomy (EUS-HGS), an echoendoscope is advanced to the gastric cardia to puncture the ducts in segment 2 or 3 (B2 or B3) [1]. As proximal migration of a stent can be fatal, endoscopists usually prefer to use a long stent [2,3]. We describe a case in which an HGS metal stent was surgically removed because of its recurrent dislocation into the esophagus, with accompanying vomiting.

A 68-year-old woman with hilar cholangiocarcinoma presented with cholangitis. An endoscopic retrograde cholangiopancreatography (ERCP) was performed, but after insertion of bilateral metal stents $(8 \mathrm{~mm} \times 8 \mathrm{~cm}$; LCD Biliary, Taewoong, Korea) into the right anterior and B3 ducts, the B2 duct still showed isolated dilatation and the patient continued to have fever and jaundice. Endoscopic ultrasound (EUS)-guided antegrade stenting $(8 \mathrm{~mm} \times 6 \mathrm{~cm}$; LCD Biliary, Taewoong, Korea) of the B2 duct across the previously inserted stent was therefore performed. An EUS-HGS was also performed using a fully covered metal stent $(6 \mathrm{~mm} \times 10 \mathrm{~cm}$; Bonastent Biliary, Standard Sci Tech Inc., Korea) (\$ Fig. 1). Following the stenting and HGS procedure, the patient's symptoms improved, but the HGS stent migrated into the esophagus, which was accompanied by vomiting ( Fig.2). At first, the stent was pushed back into the gastric cavity using forceps; however, the patient experienced recurrent vomiting and radiographic imaging showed repeat stent dislocation into the esophagus. In an attempt to prevent further stent dislocation, another fully covered metal stent was inserted through the previous stent; however, dislocation still occurred. We then tried to anchor the stent to the stomach by placing a double-pigtail plastic stent $(5 \mathrm{Fr} \times 7 \mathrm{~cm}$, Zimmon; Cook

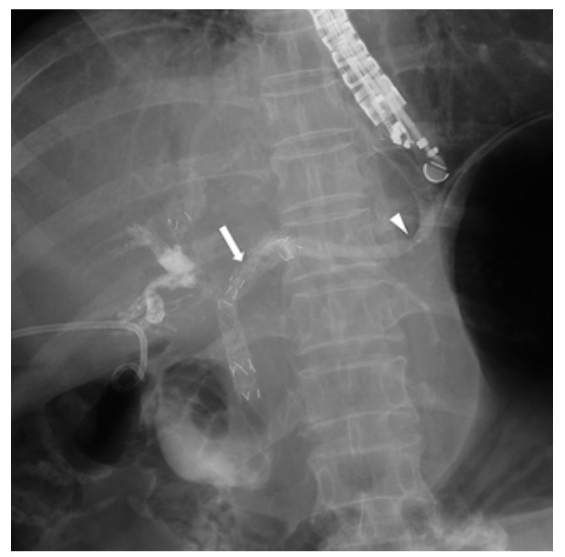

- Fig. 1 Radiographic image showing the endoscopic ultrasound-guided hepaticogastrostomy (arrowhead) and the antegrade stent (arrow).
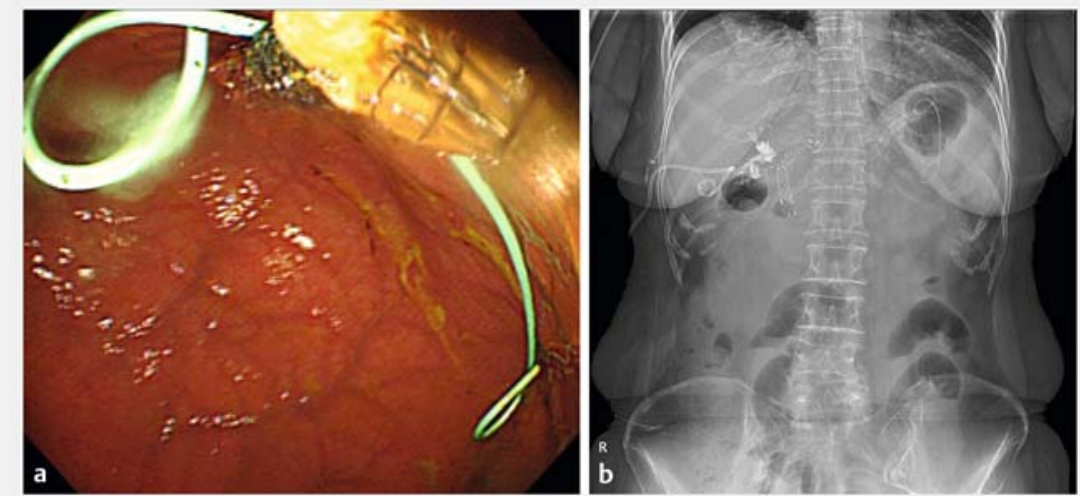

- Fig. 3 Appearance after placement of a double-pigtail stent across the previously inserted metal stent: $\mathbf{a}$ on endoscopic view $\mathbf{b}$ on fluoroscopic view.

Medical, USA) at the distal tip of the HGS stent ( $\triangleright$ Fig. 3 ). Instead of providing anchorage however, the metal stent migrated into the stomach ( $>$ Fig. 4 ). Therefore, we removed the plastic stent. Finally, the HGS stent was removed during a laparoscopy ( $\downarrow$ Video 1 ). After stent removal, the patient no longer experienced vomiting.
Endoscopists should be aware of this adverse event before performing EUS-HGS.

Endoscopy_UCTN_Code_CPL_1AL_2AD

Competing interests

None 


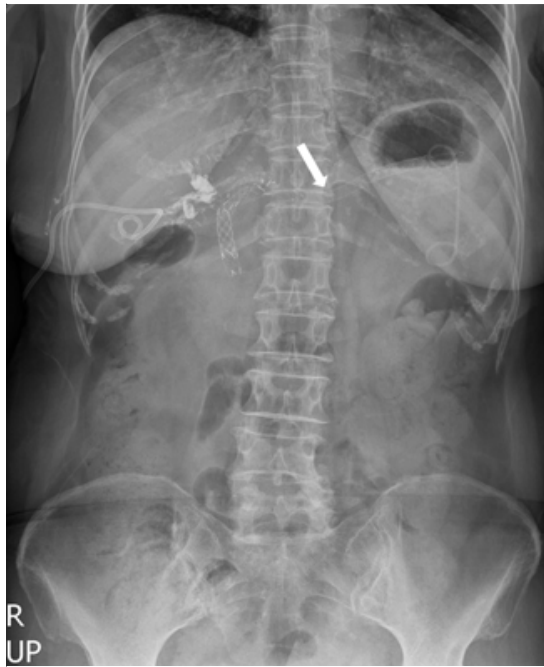

- Fig.4 Abdominal radiograph showing proximal migration of hepaticogastrostomy stent owing to the anchoring plastic stent (arrow).

Hoonsub So ${ }^{1}$, Jae Hoon Lee ${ }^{2}$, Jin Hee Noh', Sung Woo Ko', Jun Seong Hwang', Dongwook $\mathrm{Oh}^{1}$, Tae Jun Song ${ }^{1}$

1 Division of Gastroenterology, Department of Internal Medicine, University of Ulsan College of Medicine, Asan Medical Center, Seoul, South Korea

2 Division of Hepato-Biliary and Pancreatic Surgery, Department of Surgery, University of Ulsan College of Medicine, Asan Medical Center, Seoul, South Korea

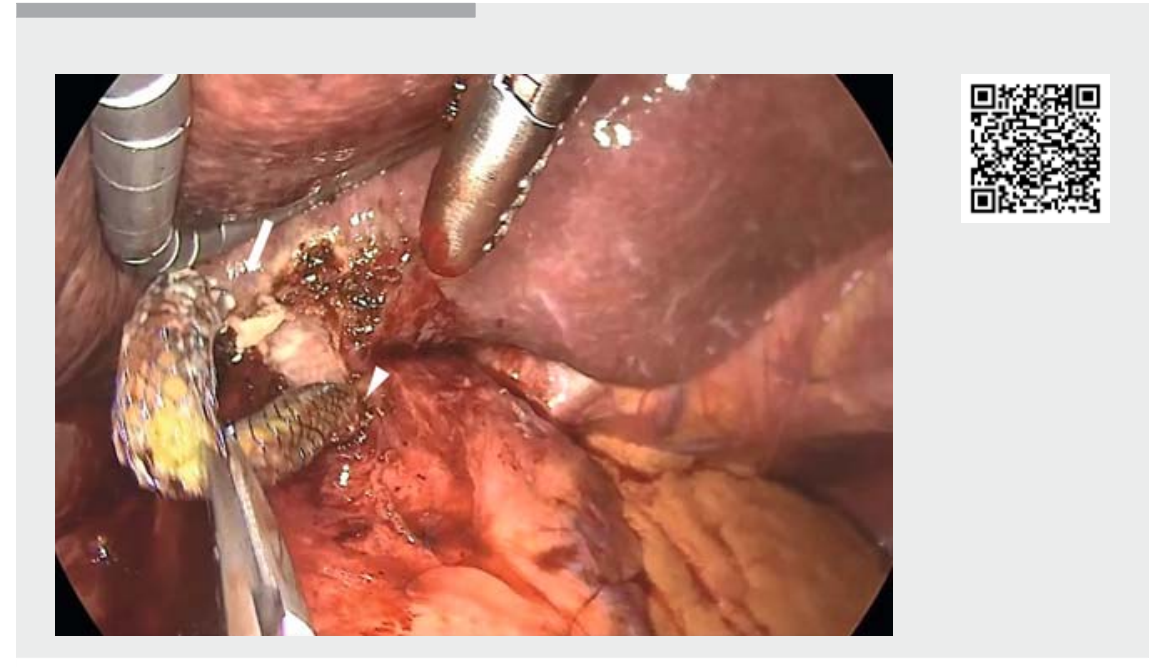

Video 1 Laparoscopic removal of the hepaticogastrostomy stent after dissection, with the fistula between the stomach and the liver being closed surgically.

Corresponding author

\section{Tae Jun Song, MD, PhD}

Division of Gastroenterology, Department of Internal Medicine, Asan Medical Center,

University of Ulsan College of Medicine, 88 , Olympic-ro 43-gil, Songpa-gu, Seoul, 05505 , South Korea

Fax: +82-2-30106517

drsong@amc.seoul.kr

\section{References}

[1] Ogura T, Higuchi K. Technical tips for endoscopic ultrasound-guided hepaticogastrostomy. World J Gastroenterol 2016; 22: 3945-3951

[2] Okuno N, Hara K, Mizuno N et al. Stent migration into the peritoneal cavity following endoscopic ultrasound-guided hepaticogastrostomy. Endoscopy 2015; 47 (Suppl. 01): E311

[3] Uemura RS, Khan MA, Otoch JP et al. EUSguided choledochoduodenostomy versus hepaticogastrostomy: a systematic review and meta-analysis. J Clin Gastroenterol 2018; 52: 123-130

\section{Bibliography}

DOI https://doi.org/10.1055/a-1025-1773

Published online: 15.11.2019

Endoscopy 2020; 52: E148-E149

(c) Georg Thieme Verlag KG

Stuttgart · New York

ISSN 0013-726X

\section{ENDOSCOPY E-VIDEOS}

https://eref.thieme.de/e-videos

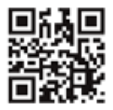

Endoscopy E-Videos is a free access online section, reporting on interesting cases and new techniques in gastroenterological endoscopy. All papers include a high quality video and all contributions are freely accessible online.

This section has its own submission website at

https://mc.manuscriptcentral.com/e-videos 